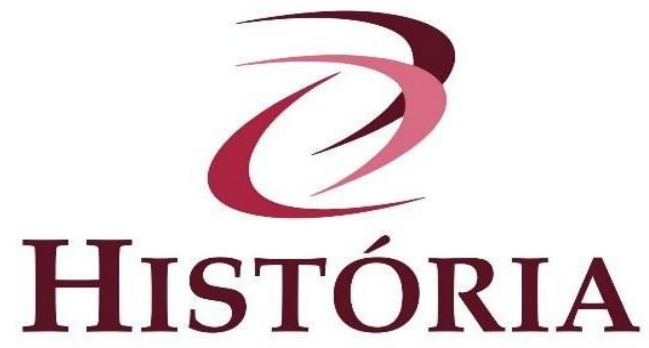

\title{
A Fundação Rockefeller e a organização e execução dos trabalhos da Comissão de Febre Amarela no Brasil
}

\section{The Rockefeller Foundation and the organization and execution of the work of the Yellow Fever Commission in Brazil}

\section{La Fundación Rockefeller y la organización y execución del trabajo de la Comisión de Fiebre Amarilla en Brasil}

O documento analisado para esta publicação, intitulado Yellow Fever Prevention: Ways and Means, Survey, Organization and Execution of the Work of the Yellow Fever Commission for Brazil, foi produzido entre 1924 e 1925, por Edward J. Scannell, integrante da Equipe Especial do International Health Board e membro da Yellow Fever Commission for Brazil. A fonte está sob a guarda do Rockefeller Archive Center e pode ser encontrada através das seguintes coordenadas: Rockefeller Foundation records, International Board/Division records, RG 5 (FA 115), Special Reports, Series 2: Special Reports - Brazil, Subseries 2_305, Box 25, Dates: 1922-1925.

O Rockefeller Archive Center (RAC) foi fundado em 1974 como uma divisão da Rockefeller University, criada, inicialmente, para servir como um repositório para os registros da Rockefeller University e de vários projetos de filantropia da família Rockefeller. Localizado em Sleepy Hollow, Nova York, seus tópicos de pesquisa vão desde a história da medicina, ciência e saúde pública até as artes, agricultura, ciências sociais, questões urbanas e políticas públicas e incluem documentos, registros pessoais e correspondência, filmes, fotografias, áudio e vídeo. Uma grande parte desses materiais audiovisuais foi digitalizada e é disponibilizada a pesquisadores de todo o mundo.

A fonte examinada está relacionada às atividades de saúde pública desenvolvidas pela Fundação Rockefeller (FR) no Nordeste do Brasil na década de 1920. A Fundação Rockefeller é uma instituição privada, filantrópica, de caráter científico, criada em 14 de maio de 1913, pelo proprietário da Standard Oil, John D. Rockefeller, seu filho John D. Rockefeller 
Jr. e Frederick Taylor Gates. Os fundadores inauguraram um estilo de filantropia em larga escala, cujo objetivo não era fornecer alívio direto aos enfermos ou empobrecidos, mas, em vez disso, buscar princípios científicos sistemáticos para curar as "causas básicas" subjacentes tanto às doenças físicas quanto aos problemas sociais.

A entidade nasceu como uma instituição internacional, de escopo global. Movida pela convicção de que a doença é a raiz de todos os males - físicos, econômicos, mentais, morais e sociais -, elegeu a saúde pública e a educação médica como campos de atuação. Assim, em 27 de junho de 1913, foi criada a International Health Commission (IHC), com o objetivo promover o "saneamento público e a disseminação do conhecimento da medicina científica" em outros lugares do mundo. Inicialmente dirigida por Wickliffe Rose, a IHC, passou por diferentes mandatos e mudanças de nome, tornando-se o International Health Board (IHB) em 1916, e a International Health Division (IHD) em 1927.

A par da interdependência sanitária e territorial, a Fundação Rockfeller pretendia impedir a propagação de doenças transmissíveis, garantindo, assim, a livre circulação de pessoas e a realização de negócios entre os países. Para tal, buscou estabelecer parcerias com países influentes e economicamente bem posicionados na América Latina, dentre estes, o Brasil. Em 1916, comissões da FR foram enviadas à América do Sul para investigar se havia uma infraestrutura de saúde voltada para o combate da febre amarela, conhecer as agências de saúde pública e instituições de educação médica nos países visitados. Uma comissão do IHB foi enviada ao Brasil para estabelecer os primeiros contatos, identificar possíveis áreas de atuação para o controle de doenças como a ancilostomíase, a malária e a febre amarela. No ano seguinte, foram celebrados acordos com os estados brasileiros interessados em desenvolver pesquisas científicas e campanhas sanitárias, sendo o estado do Rio de Janeiro o primeiro a firmar parceria com a Fundação. Em 1923, a FR estabeleceu um acordo com o governo brasileiro para erradicar a febre amarela nos estados onde a doença era recorrente, dentre estes a Bahia. Foi neste contexto que a fonte analisada foi produzida.

O documento elaborado por Edward J. Scannell revela o modus operandi do International Health Board no Brasil, com referências a estados e cidades do Nordeste Bahia, Paraíba e Ceará. As 30 páginas (considerando-se a numeração original) escritas em inglês, oferecem ao historiador informações detalhadas sobre a organização e realização do serviço de erradicação da febre amarela. Scannell orienta a investigação clínica e epidemiológica; explica quais as condições que favoreciam a proliferação de mosquitos e a endemicidade da doença em uma determinada localidade; fornece informações sobre a doença e suas variadas denominações; apresenta um modelo de inquérito epidemiológico a ser 
aplicado nas localidades investigadas; discute as condições de fornecimento, distribuição e armazenamento de água na Bahia e no Ceará. Anexos a esta espécie de manual de instruções, há um mapa de cidade não identificada, com as zonas sanitárias assinaladas; gráficos relativos ao serviço e comissões sanitárias da febre amarela em Salvador (BA), Fortaleza (CE) e em João Pessoa (PB); modelos de tabelas de controle dos serviços realizados, para serem preenchidas pelos inspetores distritais e enviadas ao inspetor geral; além de um organograma do Serviço de Febre Amarela de Salvador, com a distribuições de cargos e funções.

Logo no início do documento, o autor apresenta os passos para a implantação do serviço de erradicação da febre amarela. Scannell recomenda que o diretor obtenha mapas, estatísticas populacionais, de morbidade e de mortalidade, informações sobre altitudes, rotas e meios de transporte e também um histórico da febre amarela no país, no passado e no presente. Para determinar as áreas de incidência e endemicidade da doença, o diretor deveria levar em consideração o tamanho das aglomerações, a densidade e a composição da população (identificando-se nativos e forasteiros); a altitude, descartando-se as cidades e vilas localizadas em sítios mais elevados onde a temperatura era muito baixa, identificar as rotas de viagem e vias de comunicação e as condições de distribuição e armazenamento da água. Era igualmente importante fazer o rastreamento da febre amarela, que poderia receber diferentes denominações, e de doenças com sintomas semelhantes, tais como a febre tifoide, paratifoide, a malária e a gastroenterite.

Os especialistas da Rockefeller traziam os modelos de ciência e de ação prontos. Scannell se baseava na "teoria dos focos-chave" para orientar a identificação dos sítios onde a febre amarela se mantinha de forma endêmica ou "quase-endêmica", com potencial de se tornar um centro disseminador da doença. Segundo a teoria, a febre amarela se mantinha em um número limitado de localidades, as mais populosas, cujas condições favoreciam a procriação do Aedes aegypti e onde indivíduos não-imunes, como crianças recém-nascidas e forasteiros, por exemplo, asseguravam a transmissão da doença. Os cientistas da Rockefeller defendiam a tese de que, se eliminassem os criadouros de mosquitos nos focos-chave, onde o Aedes aegypti vivia ao lado de uma população não-imune, a febre amarela poderia ser erradicada. Para determinar os focos-chave, apoiavam-se em critérios clínicos e epidemiológicos, bem como na identificação do agente patogênico da doença.

A Bahia e sua capital se enquadravam na definição de centro endêmico dos especialistas da Rockefeller. Com 300.000 habitantes, Salvador era uma cidade litorânea, visitada por negociantes e turistas de várias partes do estado, do país e do mundo, que somados a outros indivíduos não-imunes, garantiam a transmissão da doença. Nas primeiras 
décadas do século XX, o abastecimento de água ainda era um problema em Salvador e demais cidades baianas e as formas de armazenamento em caixas d'água e em vasilhames de barro, no interior das residências, favoreciam a proliferação dos mosquitos transmissores da doença. Além destes fatores, a cidade atendia aos pré-requisitos da Fundação Rockefeller por possuir uma tradição em pesquisa de doenças tropicais e uma estrutura organizacional prévia para dar suporte às ações do IHB.

O documento elaborado por Scannell, datado de março de 1924, traz um organograma do Serviço de Febre Amarela implantado em Salvador. A fonte revela a existência de uma repartição robusta, que empregava muitos profissionais, os quais eram distribuídos, hierarquicamente, em diferentes cargos e funções. O Serviço era capitaneado por um diretor ao qual estavam diretamente subordinados um inspetor geral, três motoristas, um secretário e um assistente. O secretário-chefe e o assistente-chefe coordenavam o trabalho de um tesoureiro, um almoxarife, quatro assistentes e um guarda. Respondiam, diretamente, ao Inspetor-geral, vinte pescadores, oito oil men (encarregados de pulverizar óleo nos criadouros dos mosquitos), além dos inspetores dos dez distritos sanitários, aos quais estavam subordinados os inspetores das zonas sanitárias e seus ajudantes. $\mathrm{O}$ documento detalha e destaca a importância de cada cargo ou função, especialmente, a de inspetor geral, que deveria ser "um homem treinado, se possível, a quem o diretor possa responsabilizar pela boa execução do trabalho em toda a cidade" e dos inspetores distritais, que além de serem treinados, deveriam ser "homens de caráter, com um razoável grau de inteligência e com a capacidade de ganhar e manter o respeito de seus subordinados". A organização do serviço, assim como o número de cargos e funções a este relacionados, dependiam do número de habitantes e casas a serem inspecionadas.

Os gráficos contidos no documento examinado oferecem informações adicionais ao pesquisador, com dados interessantes sobre os serviços e comissões da febre amarela em Salvador, Fortaleza e João Pessoa. O gráfico sobre Salvador, foi elaborado pela Yellow Fever Commission em 1924. A fonte mostra a quantidade de casas inspecionadas, o número de focos, de depósitos examinados e de criatórios de mosquitos encontrados, como também o quantitativo de peixes depositados e de caixas d'água seladas por mês, considerando-se o intervalo de janeiro a dezembro. O gráfico do Yellow Fever Service - International Health Board relativo à Fortaleza, cidade com uma população de 80.000 pessoas e 13.000 domicílios, traz informações sobre a porcentagem de casas onde foram encontrados criadouros de mosquitos entre 1923 e1924. O gráfico do Yellow Fever Commission Brazil referente a João Pessoa, então denominada de Paraíba do Norte, tem a data de 1924 e também registra a 
porcentagem de casas onde foram encontrados criadouros de mosquitos. O que destaca este último dos demais são as anotações feitas quando o percentual aumenta: "Por meio da interferência, o serviço fica desmoralizado" ou "Índice novamente elevado - mostrando o que pode acontecer quando a força se torna desorganizada." Havendo um comentário quando os índices diminuem: "Índice aqui caindo rapidamente devido ao trabalho efetivo da força reorganizada."

O exame da fonte não permite saber que tipo de interferência ou quem interferiu no serviço da Yellow Fever Commission Brazil em João Pessoa. Sabe-se, contudo, que a relação dos sanitaristas brasileiros com os especialistas norte-americanos não era isenta de conflitos. A profilaxia por meio de peixes larvófagos, inseridos nos recipientes de água, era um ponto de insatisfação para os moradores das cidades, como também para os cientistas e médicos brasileiros dedicados ao combate das verminoses e doenças de veiculação hídrica. Além das mortes, decomposições e dejeções dos peixes provocarem doenças, muitas vezes, estes eram coletados em cursos de água contaminada, que, ainda que em pequena quantidade, era transferida para os porrões, potes e moringas que armazenavam a água de beber. Os comentários também podem se referir a problemas relativos à forma como serviço era organizado: uma área extensa e um grande número de casas deveriam ser inspecionados em um curto espaço de tempo, o que dava lugar, às vezes, a "arranjos" nem sempre muito ortodoxos para cumprir as metas estabelecidas pelos membros da Yellow Fever Commission for Brazil. Para garantir que trabalho fosse realizado a contento, Scannell, recomendava que os diretores, inspetores gerais e distritais visitassem as casas após a passagem dos inspetores das zonas sanitárias, pois só desta forma poderiam "julgar o real estado das coisas".

O documento que, neste momento, é inédito, é uma fonte que permite analisar o assunto não só em uma perspectiva local ou regional, como também nacional e internacional, embasa a discussão sobre as tensões existentes nas interações entre diferentes atores (médicos e cientistas nativos e comissões médico-científicas estrangeiras), sobre a produção, legitimação, circulação e aplicabilidade do conhecimento científico, como também sobre a elaboração e implantação de políticas públicas de saúde em diferentes áreas do globo. 
Figura 1 - Yellow Fever Prevention.

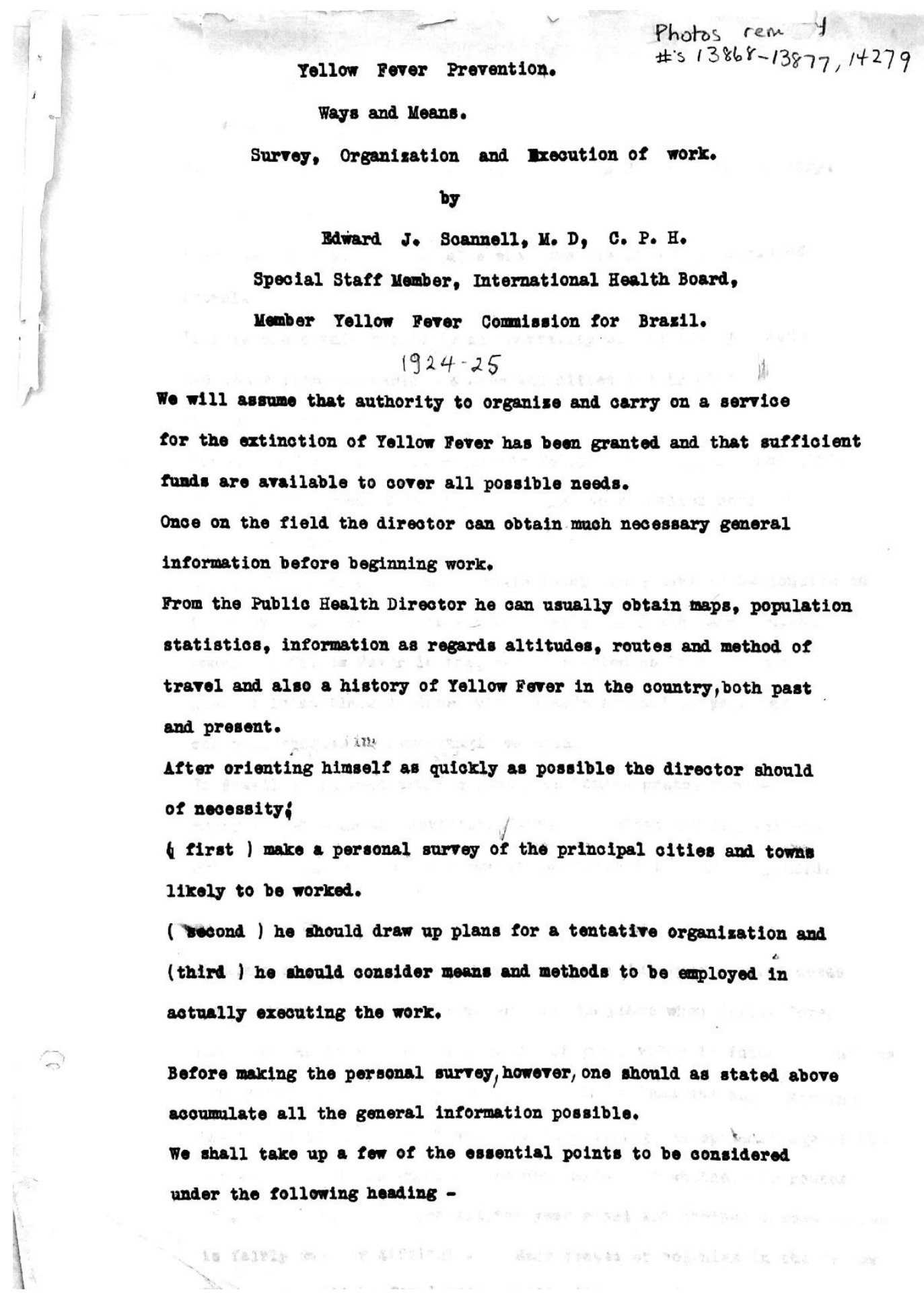

Source: Rockefeller Foundation records, International Board/Division records, RG 5 (FA 115), Special Reports, Series 2: Special Reports - Brazil, Subseries 2_305, Box 25, Dates: 1922-1925.

\section{Referências}

BATISTA, R. dos S. \& SOUZA, C. M. C. de. O curso da epidemia: a Fundação Rockefeller e os surtos de febre amarela na Bahia em 1926. Outros Tempos, São Luiz, v. 17, n. 30, p. 219243, 2020. Disponível em:

https://www.outrostempos.uema.br/index.php/outros_tempos_uema/article/view/787. Acesso 
em: 22 jul. 2021.

BENCHIMOL, J. L. et al. Cerejeiras e cafezais: relações médico-científicas entre Brasil e Japão e a saga de Hideyo Noguchi. Rio de Janeiro: Bom Texto, 2009.

CASTRO SANTOS, L. A. de; FARIA, L. R. A reforma sanitária no Brasil: ecos da Primeira República. Bragança Paulista: Edusf, 2003.

CUETO, M. (Ed.). Missionaries of science: the Rockefeller Foundation and Latin America. Bloomington: Indiana University Press, 1994.

FARLEY, J. To cast out disease: a history of the International Health Division of the Rockefeller Foundation (1915-1951). Oxford: Oxford University Press, 2004.

LÖWY, I. Vírus, mosquitos e modernidade: a febre amarela no Brasil entre ciência e política. Rio de Janeiro: Editora Fiocruz, 2006.

ROCKEFELLER ARCHIVE CENTER. Disponível em: https://rockarch.org/. Acesso em: 22 jul 2021.

Recebido: $23 / 07 / 2021$

Aceito: $30 / 07 / 2021$

Publicado:01/09/2021

\footnotetext{
* Doutora em História das Ciências e da Saúde pela Casa de Oswaldo Cruz, Fiocruz. Membro do Núcleo de Tecnologia em Saúde do Instituto Federal de Educação, Ciência e Tecnologia da Bahia. orcid.org/0000-00019716-7891. E-mail: chriscruz160@gmail.com.
} 